\title{
An Experimental Study of Production and Properties of Animal Fats Biodiesel
}

\author{
Dr. C. Solaimuthu ${ }^{1}$, Prof. S. Ashfaque Ahmed ${ }^{2}$, Prof. M. Vinoth ${ }^{2}$, \\ V. Gowri Shankar, N. Nandha Kumar and C. Karmegan \\ ${ }^{1}$ Professor cum Director (Research), Department of Mechanical Engineering, Er. Perumal Manimekalai \\ College of Engineering, Hosur - 635 117, Tamil Nadu, India (Corresponding Author) \\ ${ }^{2}$ Assistant Professors, Department of Mechanical Engineering, Priyadarshini Engineering College, \\ Vaniyambadi - 635 751, Vellore, Tamil Nadu, India \\ U.G Scholars, Department of Mechanical Engineering, Vaniyambadi - 635 751, Vellore, Tamil Nadu, India
}

\begin{abstract}
Mainly animal fats and vegetable oils are used for the production of biodiesel. Several types of fuels can be derived from triacylglycerol-containing feedstock. Biodiesel which is defined as the mono-alkyl esters of vegetable oils or animal fats. Biodiesel is produced by transesterifying the oil or fat with methanol under mild conditions in the presence of a base catalyst. This work deals with fuel production, fuel properties and coproducts with the use of glycerol which is the by-product in esterification process along with biodiesel.
\end{abstract}

Keywords: Biodiesel, Animal Fats, Transesterification, Petro-Diesel

\section{Introduction}

Internal combustion engines particularly of the compression ignition type play a major role in transportation, industrial power generation and in the agricultural sector as well. There is need to search and find ways of using alternative fuels, which are preferably renewable and also contribute low levels of gaseous and particulate emissions from internal combustion engines. In the case of agricultural applications, fuels that can be produced in rural areas in a decentralized manner, near the consumption points will be favored. The permissible emission levels can also be different in rural areas as compared to urban areas on account of the large differences in the number density of direct injection diesel engines.

\section{Literature Survey}

Different processes for biodiesel production using fats and oils as a feedstock yields fuels with different composition and properties [1,2]. Biodiesel which is defined as the mono-alkyl esters of vegetable oils or animal fats, obtained by transesterified oil or fat with an alcohol. The major reason for not using a neat vegetable oil as fuel is its high viscosity ( 28 to $40 \times 10^{-6} \mathrm{~m} 2 / \mathrm{s}$ ), which leads to operational problems in diesel engine including formation of deposits into the injector choking due to poorer atomization upon injection into the combustion chamber [1]. Transesterification of the oil reduces the viscosity of the oil to a range $\left(4.5 \times 10^{-6}\right.$ $\mathrm{m}^{2} / \mathrm{s}$ ) closer to that of petro diesel. The combustion of petroleum based fuels causes environmental problems, which threaten wild and human life, impacts on the environment and human health. Further global warming is caused of emission of $\mathrm{CO}, \mathrm{SO}_{2}$ and $\mathrm{NO}_{\mathrm{x}}$ etc as the combustion products. Its part in global warming potential has increased from year by year and now bigger than those of the domestic and industrial sector. The diesel emission contributes to the development of cancer, cardiovascular and respiratory health effects; pollution of air, water and soil; soiling; reductions in visibility and global climate change. There are many works on reliable researching and implementation and useful results come to exist. The alternative fuels must be technically acceptable, economically competitive, environmentally acceptable and easily available [3]. Research on biodiesel derived from vegetable oils and animal fats are being maintained to alternate this kind of fuels to petroleum based diesel fuel. It has been concluded by many studied that as an alternative engine biodiesel reduce the emissions of carbon monoxide (CO), hydrocarbons (HC), sulphur dioxide $\left(\mathrm{SO}_{2}\right)$, Polycyclic Aromatic Hydrocarbons (PAH), nitric Polycyclic Aromatic Hydrocarbons (nPAH) and particulate matter (PM) by $\mathrm{NO}_{\mathrm{x}}$ to increase in the exhaust as compared with diesel fuel $[4,5,6]$. Biodiesel is being produced from many of vegetable oils and animal fats. If it is produced from high quality edible oil and fats, it will resulted in high prices of raw material and biodiesel is more expensive than petroleum diesel fuel also shortage of edible oil for food purpose. Biodiesel may also be produced from less expensive animal fats including inedible tallow, pork lard and yellow grease. Animal fats are highly viscous and mostly in solid form at ambient temperature because of their high content of saturated fatty acids. The high viscous fuel leads to poor atomization of the fuel and result in incomplete combustion. Transesterification and emulsification are two main solutions that have appeared as effective methods for using animal fats in diesel engine. Animal tallow generated biodiesel offers a 
wide range of energy, environmental and economic advantage [7]. Here, Glycerol, which is a co-product in the biodiesel production, refining and unrefined. There was a considerable reduction takes place while adopting Selective Catalytic Reduction (SCR) fuelled with Madhuca India biodiesel blends [8]. The diesel engine was investigated fuelled with various blends of preheated cotton seed oil. There was increase in brake thermal efficiency and reduction in exhaust gas temperature, smoke, carbon monoxide and hydrocarbon as that of fossil diesel fuel [9]. Vegetable oil as a suitable alternate fuel for compression ignition engine is in its pure form or blended with petroleum diesel. Moreover biodiesel is better than diesel based on some of its physical properties like sulfur content, flash point, aerometric content and biodegradability [10].

\subsection{Density and Relative Density}

\section{Property of the Fuel}

The density and relative density was measured using hydrometer. The measurements are made three times and then averaged.

\subsection{Cold Flow Properties}

In measuring the Pour point, a $45 \mathrm{ml}$ sample initially at $45^{\circ} \mathrm{C}$ is cooled at specified rate and examined at interval of $3^{\circ} \mathrm{C}$ to check if the sample is still flowing. The cloud point is determined by a cloud point meter which comprises of a waveguide sensor of a total-reflection type, the wave guide sensor including a wave guide having an incidence channel, an emergency channel and a detection surface all formed on a substrate, the incidence and emergency channels intersecting along the detection surface, an incidence optical fiber connected to the entrance of the incidence channel, and an emergency optical fiber connected to the exit of the emergence channel; and a cooling/heating means in contact with the waveguide sensor for cooling/heating the waveguide sensor within a desired temperature range. The cold soaked filter is a mandatory quality control test introduced by ASTM in 2008 to prevent particulate matters in biodiesel from precipitating at low temperature to clog filters and block fuel pipes thus cutting off fuel flow to the engine. A cold filter plug apparatus model MC840 with 0.8 micron filter is used to test $60 \mathrm{ml}$ of each sample. It involves chilling the biodiesel to a predetermined point and then reheating to room temperature. The chilling and reheating processes formed mushy crystal like material that can clog the fuel filter. The biodiesel in passed through the two filters and the time in seconds it takes for cold soaked biodiesel to pass through two 0.8 micron filters and the amount of matters collected are measured.

\subsection{Kinematic and Dynamic Viscosities}

The kinematic viscosity was determined with a Herzog GmbH MP-480 that involves measuring the time for a fixed volume of the fuel to flow under gravity through a capillary at temperature of $40^{\circ} \mathrm{C}$. Kinematic viscosity = Calibration constant $\left(\times 10^{-6} \mathrm{~m} 2 / \mathrm{s}\right) \times$ mean time of flow $(\mathrm{s})$. The rook field viscometer is used to measure the dynamic and kinematic viscosity at a temperature of $40^{\circ} \mathrm{C}$.

\subsection{Flash Point}

Flash point measurements were done according to method ASTM D6751 using Kehler Model K-16270 (Pensky-Martens Closed Flash Tester).

\subsection{Higher and Lower Heating Values}

The lower heating value was obtained using the oxygen bomb calorimeter (Parr Instrument Company, US) following the ASTM D240 method.

\subsection{Calculated Cetane Number}

The cetane number of the biodiesel was calculated using equation 3 Where G is the API (American Petroleum Institute) specific gravity and T50 is the distillation temperature as $50 \mathrm{vol}$. \% fuel sample distilled and condensed in a unit of ${ }^{\circ} \mathrm{F}$.

\subsection{Acidic Number}

The acid number, which is the amount of $\mathrm{KOH}$ required neutralizing $1 \mathrm{gm}$ of fat and expressed as $\mathrm{mg}$ $\mathrm{KOH} / \mathrm{g}$, was determined by titrating with $0.01 \mathrm{~N}$ potassium hydroxide for the mixture of tested fuel and chemical reagents until the appearance of the color pink.

\subsection{Moisture Content}

The moisture content was measured by Karl-Fisher Method (ASTM D 6304) 831 KF Coulometer (Metrohm Company, Switzerland) using $5 \mathrm{ml}$ of the samples. 


\subsection{Water and Sediment}

Water and sediment content were obtained by centrifuge model HNS II by Thermo Electron Corp, US. $100 \mathrm{ml}$ of each sample was poured into a centrifuge tube and spun at $800 \mathrm{rev} / \mathrm{min}$ for 10 minutes and the volume of water and sediment was read to the nearest $0.005 \mathrm{ml}$.

\subsection{Carbon Residue}

Carbon residue was determined following standard procedure which involved heating a sample of the fuel to $500^{\circ} \mathrm{C}$ in nitrogen filled chamber at controlled rate to ensure that the sample cokes and does not combust. The volatile compounds formed were then with flushed from the chamber with nitrogen after which the mass remaining was determined. The aim of the test was to simulate the formation of carbon deposits in the engine by the fuel.

\subsection{Sulfated Ash}

Isotemp muffle furnace was used for the test. The residue was allowed to cool down and thereafter treated with sulfuric acid and heated to $750^{\circ} \mathrm{C}$ until oxidation of carbon was complete. The resulting ash was then cooled, retreated with sulfuric acid and heated to $750^{\circ} \mathrm{C}$ to constant weight. After which the percentage weight was calculated.

\subsection{Glycerine Content}

The wet Chemical AOCS method for determining glycerol, methanol, AOCS Official method Ca 14-56 entitled "Total, free and combined glycerol Iodometric-periodic Acid method as well as methanol Content" was used. It is similar to the method prescribed in the ASTM standard but easier to perform. It was also used for the determination of monoglycerides, diglycerides and triglycerides.

\subsection{Copper Strip Corrosion Test}

Copper strip corrosion test was conducted according to ASTM D130 protocol. A polish copper strip was immersed in $50 \mathrm{ml}$ sample of the oil and methyl ester for 3 hours at $50^{\circ} \mathrm{C}$. At the expiration of the duration each strip was washed in a standard solvent and the result were compared with standard description of tarnished and corrosion.

\subsection{Distillation Temperatures}

During the vacuum distillation test, the system pressure was set at between $1 \mathrm{kPa}$ and $83 \mathrm{kPa}$ and was made to correspond to 5 to $95 \mathrm{vol} \%$ in a step of $5 \mathrm{vol} \%$ of the liquid fuel distilled and condensed.

\subsection{Metal Analysis}

For metal analysis $50 \mathrm{ml}$ of samples were prepared by diluting 1:10 with kerosine. The dilution was to eliminate possible viscosity effect that may affect accuracy. The Teledyne fuel pro biodiesel metal analyzer was calibrated with standards prepared by diluting plasma pure biodiesel stock standards. The standard concentrations are $0.00,10.00,20.00$, and $30.00,40.00 \mathrm{ppm}$ of $\mathrm{Na}, \mathrm{K}, \mathrm{Ca}, \mathrm{Mg}, \mathrm{P}$ and $\mathrm{S}$.

\subsection{Colour}

The colours of the oil, biodiesel and blends are observed visually.

The properties of the Petro-diesel, Ethanol and Animal fats biodiesel are shown in table 1.

Table 1 Property of Neat Petro-Diesel, Ethanol and Neat Animal Fats Biodiesel

\begin{tabular}{|c|l|c|c|c|}
\hline S. No & \multicolumn{1}{|c|}{ Name of the Property } & Neat Petro-Diesel & Ethanol & $\begin{array}{c}\text { Neat Animal Fats } \\
\text { Biodiesel }\end{array}$ \\
\hline 1 & Specific Gravity in Dimension Less & 0.85 & 0.81 & 0.87 \\
\hline 2 & Kinematic Viscosity at 40 deg c & 3.05 & 0.82 & $4.0-6.0$ \\
\hline 3 & Calorific Value in kj/kg & 42,800 & 29844 & 36000 to 38000 \\
\hline 4 & Cetane Number in Dimensional Less & 47 & $5-8$ & 57 \\
\hline 5 & Flash Point in deg C & 85 & 13 & 165 \\
\hline 6 & Pour Point in deg C & -4 & --- & -5 to10 to15 \\
\hline 7 & Cloud Point in deg C & -15 to -5 & -- & 0.14 \\
\hline 8 & Acid Value in mg KOH/g & 0.03 & --- & \multirow{2}{*}{} \\
\hline
\end{tabular}




\subsection{Transestrification of Animal Fats}

\section{Production of Biodiesel}

Widely used and accepted process to reduce the viscosity of triglycerides in animal facts is transesterification. The transesterification of animal fats, a triglyceride reacts with an alcohol in the presence of a strong acid or base, producing a mixture of fatty acid alkyl esters and glycerol. About $0.3 \%$ by volume of base catalyst is dissolved in $10 \%$ by volume of methyl alcohol to prepare alkoxide, which is required to activate the alcohol. Around one hour vigorous stirring is done in a closed container until the alkali is dissolved completely. The alcohol-catalyst mixture was then transferred to the reactor containing moisture free animal fats. A continuous stirring of the resulting mixture at temperature between 60 deg to $65 \mathrm{deg} \mathrm{C}$ is carried out for one hour with water or air cooled condenser. The resulting mixture was then taken out and poured into the separating funnel to separate glycerin (glycerol) from the mixture to get the Animal Fats Methyl Ester (AFMS) or Animal Fats Biodiesel. Water washing is done in order to remove alcohol and impurities from the biodiesel.

\subsection{Glycerin}

The production glycerin (by product), after the transesterification process, can be sent it to soap manufacturing process as main product. Hence, the cost of glycerin may be reduced while calculating the cost of biodiesel.

\section{Conclusions and Recommendations}

The test results, it could be concluded that, the production of biodiesel from animal fats is a new option for vegetable oil biodiesel and can be efficiently use in diesel engine. The animal fats biodiesel can be used as solvent or properties improver the petro-diesel blends. It is the better choice to use biodiesel produced from waste animal fats in order to overcome the problems related to petro-diesel price hike.

\section{References}

[1] Gerhard Knothe, Biodiesel and Renewable diesel: A comparison, Progress in Energy and combustion science, 36, 2010, 364-373.

[2] G Knothe, J. Krahl and J. Van Gerpen, Editors. The biodiesel handbook, 2005. Champaign, IL, USA.

[3] A.C Lloyd and T.A. Cackette, Diesel engine: environmental impact and control, J Air Waste Manage Assoc, 51, $2001,809-47$.

[4] M Zheng, M.C. Mulenga, G.T. Reader, M. Wang, D.S.K. Ting and J. Tjong, Biodiesel engine performance and emissions in low temperature combustion. Fuel, 87 (6), 2008, 714-22.

[5] A.K Agarwal and K. Rajamanoharan, Experimental investigation of performance and emissions of karanja oil and its blends in a single cylinder agricultural diesel engine, Applied Energy, 86, 2009, 86, 106-12.

[6] YF Lin, Wu YPG, C.T. Chang. Combustion characteristics of waste-oil produced biodiesel/diesel fuel blends. Fuel, 86, 2007, 17721780 .

[7] RG Nelson and M.D. Schrock, Energetic and economic feasibility associated with the production, processing and conversion of beef tallow to a substitute diesel fuel. Biomass Bioenergy, 30, 2006, 584-91.

[8] C Solaimuthu, S. Chitra, P. Rajasekaran, B. Abjith, G. Jayaprakasan, V. Arun Kumar and R. Lokesh, NO $O_{x}$ reduction of diesel engine with Madhuca Indica biodiesel using Selective Catalytic Reduction (SCR) in different flow rates, Journal of Mechanical and Civil Engineering, International Organization of Scientific Research, 10 (5), 2014, 28-34.

[9] M Martin and D. Prithviraj, Performance of Pre-heated Cottonseed Oil and Diesel Fuel Blends in a Compression Ignition Engine, Jordan Journal of Mechanical and Industrial Engineering, 5(3), 2011, 235-240.

[10] Syed Ameer Basha, K. Raja Gopal and S. Jebaraj, A review on biodiesel production, combustion, emissions and performance. Renewable and Sustainable Energy Reviews, 13, 2009, 1628-1634. 